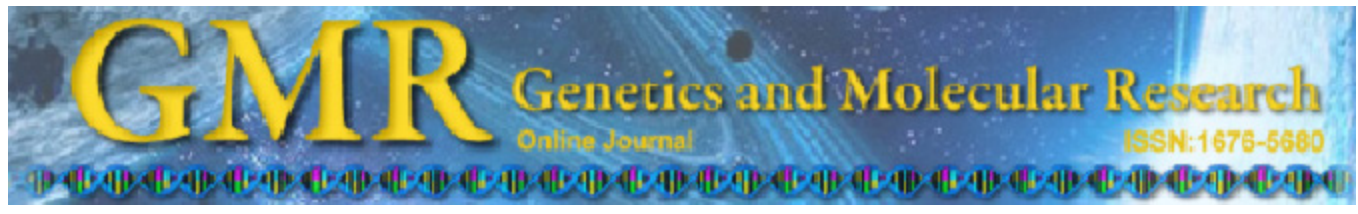

\title{
A potential protective role for thiamine in glucose-driven oxidative stress
}

\author{
B. Palabiyik, F. Jafari Ghods and E. Onay Ucar
}

Department of Molecular Biology and Genetics, Faculty of Science, Istanbul University, Istanbul, Turkey

Corresponding author: B. Palabiyik

E-mail: bediag@istanbul.edu.tr

Genet. Mol. Res. 13 (3): 5582-5593 (2014)

Received July 22, 2013

Accepted October 25, 2013

Published July 25, 2014

DOI http://dx.doi.org/10.4238/2014.July.25.13

\begin{abstract}
The relationship between glucose repression and the oxidative stress response was investigated in Schizosaccharomyces pombe wild type cells $\left(972 h^{-}\right)$and glucose repression resistant mutant type cells (ird11). We aimed to reveal the mechanism of simultaneous resistance to glucose repression and oxidative stress in ird11 mutants. Compared to the wild type, the expression of the sty 1 gene was not altered in the ird11 mutant under normal growth conditions, but decreased after exposure to $\mathrm{H}_{2} \mathrm{O}_{2}$. This effect was clearly explained by the immunoblotting results, which showed elevated levels of a much more stable phosphorylated form of Sty1 mitogen-activated protein kinase in the ird11 mutant. Increased ght 3 gene expression levels were also found, which may play a role in protecting the ird11 mutant from the deleterious effects of oxidative stress. In addition, decreased expression levels of glycolytic enzyme enolase- and thiamine synthesis/ transport-related genes were detected. This might have resulted from the flux redirection toward mitochondrial respiration, which would enhance NADPH generation to prevent the high reactive oxygen species accumulation that is generated by respiration. Some evidence supported a flux shift toward fermentation as well as respiration. We conclude that a defect in the glucose-sensing signaling pathway in
\end{abstract}


ird11 mutants likely causes erroneous low glucose-sensing signaling and high ATP production. This most likely occurs because high glucose availability in the medium induces an impairment in the respiratory chain and fermentation balance in these cells, which might explain the glucose repression and oxidative stress resistance in ird11 compared to the wild type.

Key words: Oxidative stress; Glucose metabolism; Glucose transport; Thiamine; Hydrogen peroxide; Schizosaccharomyces pombe

\section{INTRODUCTION}

Glucose is an essential source of carbon and energy for many organisms. In eukaryotes, glucose is mainly assimilated through the respiration in mitochondria by being reduced to $\mathrm{CO}_{2}$ and $\mathrm{H}_{2} \mathrm{O}$, thereby generating ATP for maximum energy yield in the presence of oxygen. However, the Crabtree-positive yeast species, Saccharomyces cerevisiae and Schizosaccharomyces pombe, undergo aerobic fermentation in which glucose is predominantly fermented to ethanol even in the presence of oxygen (Walker, 1998; Flores et al., 2000).

In $S$. pombe, glucose is sensed by a heterotrimeric $\mathrm{G}$ protein-coupled receptor, which generates a downstream signal through a cAMP-dependent protein kinase A (PKA) pathway (Hoffman, 2005). Subsequently, glucose uptake and glycolysis is induced (Rolland et al., 2001) and the use of alternative carbon sources, glyconeogenetic pathways, and respiration in mitochondria are repressed, eventually resulting in the accumulation of reactive oxygen species (ROS) (Carlson, 1999). Some of the genes related to glucose sensing and signaling are git3, gpa2, git5, git11, git1, git7, git10 (Byrne and Hoffman, 1993; Nocero et al., 1994), and cyr 1 , encoding adenylate cyclase, pkal, encoding the PKA catalytic subunit, and cgs 1 , encoding the PKA regulatory subunit (Maeda et al., 1994). Heiland et al. (2000) identified six genes (ght1-ght6) encoding monosaccharide transporters. Among these, Ght1, Ght2, and Ght5 have substrate specificity for D-glucose, whereas the specificity of Ght6 is to D-fructose. Furthermore, the activity of Ght3 is optimal at low glucose concentration $(0.2 \%), 2 \%$ D-gluconate, or $2 \%$ maltose. Recently, it was reported that glucose depletion or respiratory growth on nonfermentable carbon sources leads to an increased oxidative stress response (Chen et al., 2003; Madrid et al., 2004; Kim et al., 2006; Chen and Runge, 2009) and extends life span in $S$. pombe (Lin et al., 2002; Roux et al., 2009, 2010).

In $S$. pombe, the multistep phosphorelay system and the mitogen-activated protein kinase (MAPK) pathway govern the transcriptional regulation in response to oxidative stress, which is generated by the accumulation of ROS caused by both the incomplete reduction of $\mathrm{O}_{2}$ during respiration and exposure to a variety of chemicals and metals. This cascade includes a conserved set of three protein kinases (MAPKKK, MAPKK, and MAPK), which triggers phosphorylation of Sty1 after exposure to stress, leading to nuclear localization of Sty1 (Marshall, 1994). MAPK Sty1 is a major regulator in the oxidative stress response, and is similar to mammalian p38 and HOG1 in S. cerevisiae (Shieh et al., 1997). Phosphorylated Sty1 phosphorylates two transcription factors, Atf1 and Pap1, to activate and to make them more stable; Atf1 is constitutively localized in the nucleus and is active even in absence of Sty1 (Wilkinson et al., 1996; Lawrence et al., 2007; Sansó et al., 2008). Atf1 can bind to a b-ZIP 
small transcription factor, Pcr1, thus forming a heterodimer that can bind to stress response elements, and induces a set of genes that defend against some environmental stressors. Stressresponse genes can be activated in both a Pcr1-dependent and Pcr1-independent manner by the binding of Atfl to related DNA elements (Reiter et al., 2008). These transcription factors activate or induce the expression of anti-oxidant genes such as cytoplasmic catalase (ctt 1$)$, glutathione peroxidase $(g p x 1)$, thioredoxinreductase $(\operatorname{tr} 1)$, thioredoxin $(\operatorname{tr} x 2)$, neutral trehalaz $\left(n t p 1^{+}\right)$, glutathionreductase $(\operatorname{pgr} 1)$, and superoxide dismutase SOD (sodl) (Feldmann, 2010).

In this study, the mechanism(s) of protection from the damaging effects of oxidative stress were investigated by using the resistant glucose repression S. pombe mutant (ird11) (Kig et al., 2005), which is affected by glucose signaling in a different manner than that caused by glucose deprivation (Palabiyik et al., 2012).

During our investigation into the possible relationship between glucose repression and the oxidative stress response, we made the unexpected discovery that these cells display the same characteristics as diabetic cells in response to glucose since the regulatory mechanisms of glucose usage are highly conserved between $S$. pombe and human cells. Although the glucose concentration in standard culture media for yeast is approximately 20-30 times higher than that in normal human blood, S. pombe cells optimally divide at the same conditions (Pluskal et al., 2011). Chen and Runge (2009) revealed that calorie restriction (0.1-0.3\% glucose) promotes efficient cell cycle exit and extends longevity. For this reason, $S$. pombe cells may be used as a model organism to better understand the damaging effects of high glucose-induced oxidative stress in diabetic patients.

\section{MATERIAL AND METHODS}

\section{Chemicals and reagents}

Anti-phospho-p38 MAPK (Tyr182) polyclonal antibody and goat anti-rabbit IgG (horseradish peroxidase-conjugated) antibody were purchased from Thermo Scientific (USA). The ECL-Plus Western Blotting Detection system was purchased from Amersham (Piscataway, NJ, USA). Other reagents were obtained from Sigma-Aldrich (USA).

\section{Yeast strains and media}

Wild type $S$. pombe Lindner Liquifacience $\left(972 \mathrm{~h}^{-}\right)$and the glucose-repression-resistant mutant (ird11) (Kig et al., 2005) were used in this study. A selective medium consisting of $0.5 \%$ yeast extract, $3 \%$ sucrose, and $400 \mu \mathrm{g} / \mathrm{mL} 2$-deoxy-D-glucose was prepared for the $\mathrm{ird} 11$ mutant, whereas the wild type was cultured in standard rich medium (YEL).

\section{RNA isolation}

S. pombe cells were grown to the logarithmic phase in YEL at $30^{\circ} \mathrm{C}$. The cultures of each strain were divided into two groups: a control and test group. For test groups, the $2 \mathrm{mM}$ optical density (OD) $)_{50}$ level, which was determined previously (Pekmez et al., 2008) in cells cultured in our department, was applied for $1 \mathrm{~h}$. Total RNA was extracted from cells using the High Pure RNA Isolation Kit (Roche) in accordance with manufacturer instructions. 


\section{Real-time polymerase chain reaction (RT-PCR)}

RT-PCR was performed with the Stratagene FastStart SYBR Green Master Kit (Roche) using the synthetic first-strand cDNA as a template following manufacturer instructions. Briefly, the reaction mixtures, consisting of $25 \mu \mathrm{L}$ FastStart SYBR Green Master, 0.2 $\mu \mathrm{M}$ of each forward and reverse primers, $0.1 \mu \mathrm{g}$ cDNA, were filled up to $50 \mu \mathrm{L}$ with ultrapure nuclease-free water. The PCR conditions were as follows: $95^{\circ} \mathrm{C}$ for $10 \mathrm{~min}$ (pre-incubation), followed by 40 cycles of $95^{\circ} \mathrm{C}$ for $10 \mathrm{~s}, 53^{\circ} \mathrm{C}$ for $10 \mathrm{~s}$, and $72^{\circ} \mathrm{C}$ for $20 \mathrm{~s}$. The final step included a gradual temperature increase from 55 to $95^{\circ} \mathrm{C}$ at a rate of $1^{\circ} \mathrm{C} / 10 \mathrm{~s}$ to enable melting curve data collection. A non-template control was run, and serial dilutions $(1,1: 10$, and 1:100) of the reference gene, actin (act1), and the target genes were included in every assay. Amplification specificity of each reaction was verified by melting curve analysis. Expression levels were normalized against the reference gene, act1. Relative gene expression levels were determined according to the method of Pfaffl (2001).

\section{DNA microarray}

For DNA microarray analysis, preparation of double stranded cDNA was carried out using the SuperScript Double-Stranded cDNA Synthesis Kit according to the NimbleGene Arrays User's Guide (Invitrogen). Fragmentation and Cy3 labeling, hybridization, washing, staining, scanning, and data normalization steps were carried out by GenMar (Izmir, Turkey). Finally, bioinformatic analysis was performed using the DNASTAR software, as recommended by NimbleGene.

\section{Cell disruption}

Exponentially grown wild type and ird 11 mutant cells under the assay conditions were harvested by centrifugation at $4000 \mathrm{~g}$ for $5 \mathrm{~min}$ at $4{ }^{\circ} \mathrm{C}$, and resuspended in $200 \mu \mathrm{L}$ lysis buffer, containing $50 \mathrm{mM}$ Tris buffer, $\mathrm{pH} 6.8,150 \mathrm{mM} \mathrm{NaCl}, 5 \mathrm{mM}$ ethylenediaminetetraacetic acid (EDTA), 10\% glycerol, $100 \mathrm{mM}$ dithiothreitol, and protease inhibitor cocktail. The cells were disrupted with 0.5 - $\mathrm{mm}$ acid-washed glass beads (Sigma) for $10 \mathrm{~min}$ at 60 -s intervals, interspersed with periods of cooling in an ice-bath. Cellular debris was removed by centrifugation at 20,000 $\mathrm{g}$ for $5 \mathrm{~min}$ at $4^{\circ} \mathrm{C}$. The supernatant was collected and protein concentrations of cell-free crude extracts were determined by the Bradford assay.

\section{Sodium dodecyl sulfate-polyacrylamide gel electrophoresis (SDS-PAGE) and Western blot analyses}

For SDS-PAGE and Western blot analysis, protein extracts were denatured in sample buffer containing $25 \mathrm{mM}$ Tris-HCl, pH 6.8, 2\% SDS, 10\% glycerol, 10\% 2-mercaptoethanol, and $0.002 \%$ bromphenol blue, and boiled for $3 \mathrm{~min}$. Fifty micrograms protein per well were analyzed by $10 \%$ SDS-PAGE. After electrophoresis, proteins were transferred onto polyvinyldifluoride membranes using a BIO-RAD Semi-Dry apparatus. Membranes were blocked with 5\% bovine serum albumin Fraction V (in Tris-buffered saline with Tween) at room temperature for $1 \mathrm{~h}$. Primary antibody against phospho-p38 MAPK was used at 1:500 for $1 \mathrm{~h}$ at room 
temperature. Peroxidase-conjugated goat anti-rabbit secondary antibody was used at 1:100 for $1 \mathrm{~h}$ at room temperature. Protein bands were detected by incubating the membranes with ECL-plus. Quantitative protein levels were evaluated with the ChemiDoc MP and ImageLab 4.0.1 software (BIO-RAD).

\section{Statistical analysis}

Data are reported as means $\pm \mathrm{SD}$ with $\mathrm{N}$ denoting the number of experiments. Statistical comparisons were conducted using the one-way analysis of variance (ANOVA) module of the GraphPad Prism 5 statistical software. Differences in mean values were considered to be significant when $\mathrm{P}<0.05$.

\section{RESULTS}

\section{Activation of Sty1 in oxidative stress-resistant mutant of $S$. pombe (ird11)}

We compared the expression level of the sty 1 gene encoding MAPK Sty1p, which increases the expression of various stress-responsive genes through the activation of the Atflp and Pap1p transcription factors in S. pombe (Madrid et al., 2004), both in ird11 and wild type cells. In this study, no significant increase was observed in styl expression in ird11 under the nonstressed condition, whereas the expression level of styl decreased in ird11 under the stressed condition. The expression level of styl was significantly increased in wild type cells under the stressed condition (Figure 1). Phosphorylated Sty1 was analyzed by immunoblotting with antiphospho-p38 $\left(\mathrm{Thr}^{182}\right.$ ) in wild type and ird11 mutant cells treated with and without $\mathrm{H}_{2} \mathrm{O}_{2}$ (Figure 2). The level of phosphorylated Sty1-MAPK increased under the non-stressed condition, whereas the level of this protein decreased dramatically under the stressed condition in ird11.

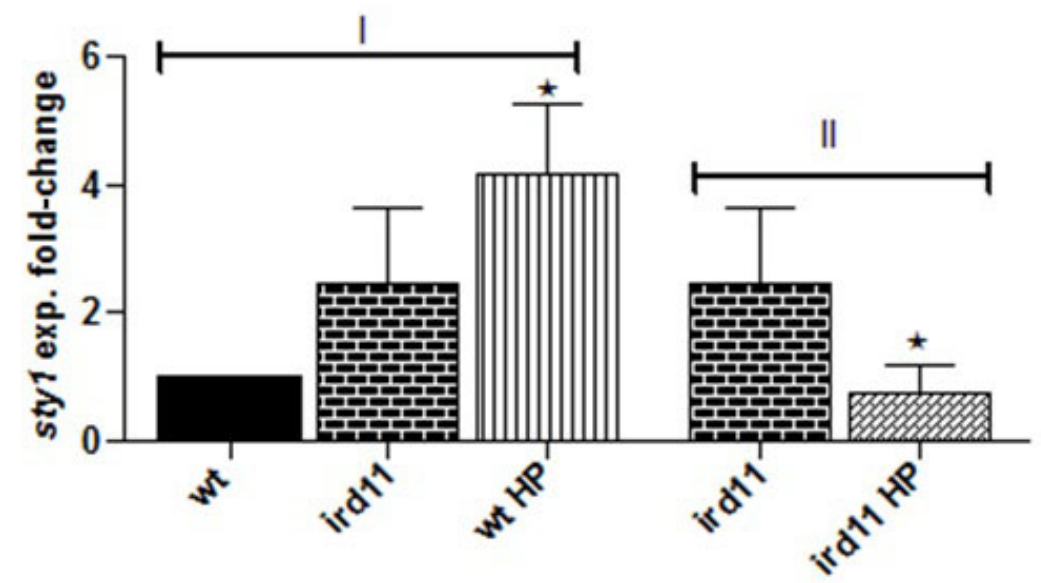

Figure 1. Expression level of the stylgene relative to actl gene. Expression levels of the stylgene in wild type and ird 11 mutant cells treated with $\mathrm{H}_{2} \mathrm{O}_{2}$ or untreated, after growth in rich media containing $2 \%$ glucose (repressed media), were determined according to the Pfaffl method. Significant differences between: (I) untreated wild type and untreated $\mathrm{ird} 11$ and treated wild type cells, (II) untreated and treated ird 11 cells were evaluated by the Student $t$-test. $* \mathrm{P}<0.05$. wt $=$ wild type; $\mathrm{HP}=$ treated with $\mathrm{H}_{2} \mathrm{O}_{2}$. 


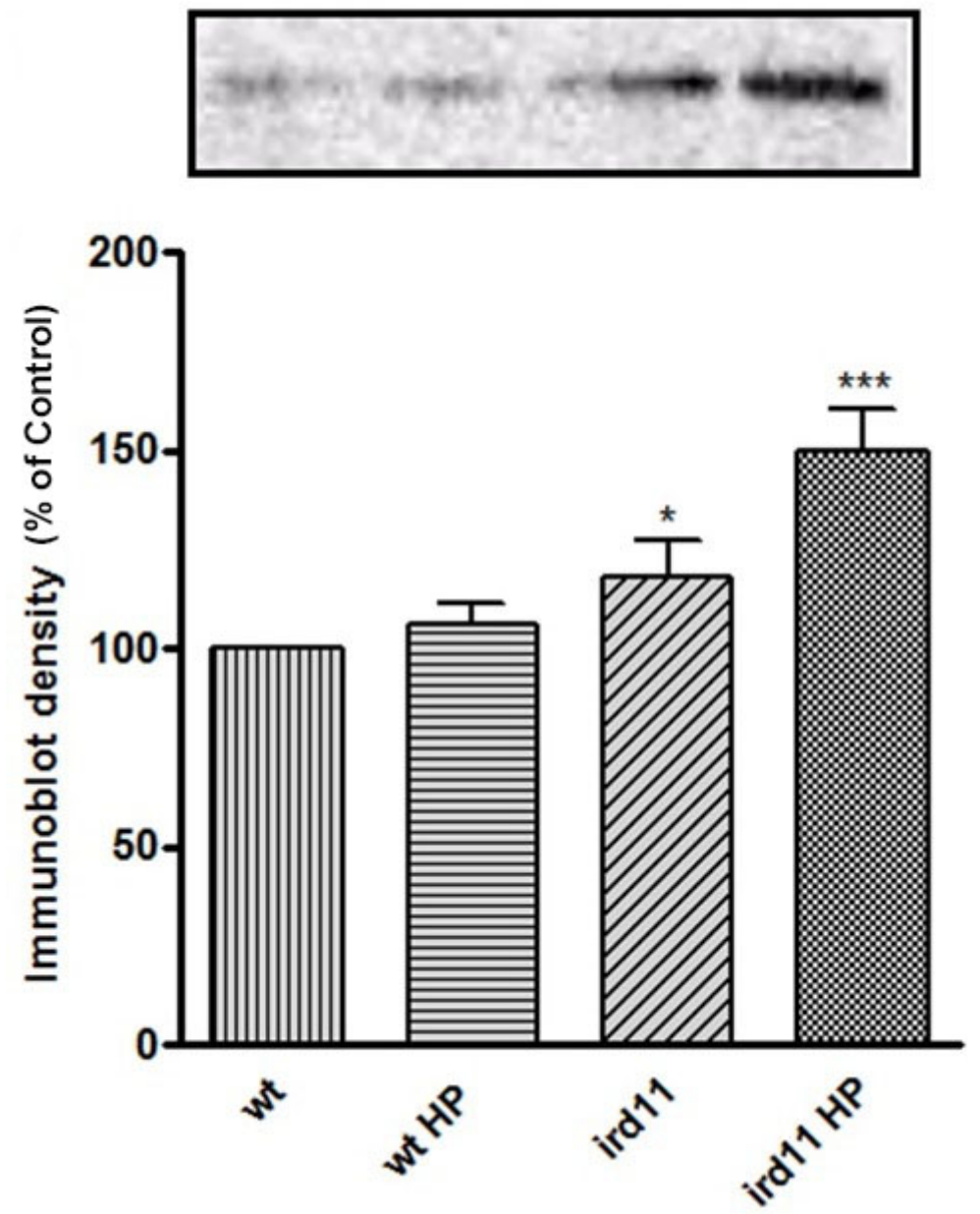

Figure 2. Detection of phosphorylated Sty1 by immunoblotting. Phosphorylated Sty1 protein was analyzed by immunoblotting with anti-phospho-p38 $\left(\mathrm{Thr}^{182}\right)$ as described in "experimental procedures" in wild type and ird11 mutant cells treated with $\mathrm{H}_{2} \mathrm{O}_{2}$ or untreated, after grown in rich media containing $2 \%$ glucose (repressed media). All results were evaluated by the Student $t$-test: $* \mathrm{P}<0.05 ; * * * \mathrm{P}<0.0001$. wt $=$ wild type; $\mathrm{HP}=$ treated with $\mathrm{H}_{2} \mathrm{O}_{2}$.

\section{Scanning of the glucose repression- and oxidative stress response-related genes in microarray data sets}

Microarrays were used to follow the global changes in gene expression before and after exposure to $\mathrm{H}_{2} \mathrm{O}_{2}$ in ird11 and wild type cells. In these cells, the expression levels of genes induced or repressed more than 2-fold were analyzed. Comparing ird11 and wild type (ird $11 \mathrm{C} / \mathrm{wtC}), 88$ genes were upregulated and 84 genes were downregulated. After exposure to $\mathrm{H}_{2} \mathrm{O}_{2}, 152$ genes were upregulated and 58 were downregulated (wtHP/wtC). In addition, by comparing ird11 cells before and after stress conditions (ird11HP/ird11C), the upregulation of 28 genes and the downregulation of 91 genes were observed. 
In order to investigate a possible relationship between glucose repression resistance and stability against oxidative stress in the ird 11 mutant, genes related to glucose sensing and signaling, carbohydrate metabolism, and the stress response were scanned in a microarray assay. There were no significant changes in the expression levels of genes related to glucose sensing through the cAMP signaling pathway, whereas decreased expression levels for 4 genes and increased expression of 1 gene related to overall signaling pathways were observed. Expression levels of two hexose transporters, Ght8 (located in the mitochondrial membrane) and Ght3, decreased by approximately 2 -fold and increased by 5 -fold, respectively. These findings confirmed the results of a previous study, which showed that changes in the ght 3 expression level were induced by low glucose concentration $(0.2 \%), 2 \%$ D-glutathione, or $2 \%$ maltose (Heiland et al., 2000). Among the genes related to carbohydrate metabolism, downregulation of 8 genes along with upregulation of only 1 gene were detected. Furthermore, the upregulation of 7 genes and the downregulation of 1 gene that play roles in the purine and pyrimidine biosynthesis pathways were found. The GenBank accession numbers, description, and fold change in each gene are shown in Table 1.

Table 1. Changes in expression of glucose repression- and oxidative stress response-related genes.

\begin{tabular}{|c|c|c|c|c|c|}
\hline Function & SEQ_ID & Name & wtHP/wtC & $\operatorname{ird} 11 \mathrm{C} / \mathrm{wtC}$ & $\begin{array}{c}i r d 11 \mathrm{HP} \\
i r d 11 \mathrm{C}\end{array}$ \\
\hline \multirow[t]{5}{*}{ Signalling } & SPAC4G8.13c & Calcineurin responsive transcription factor Prz1 & 0.396 & 0.496 & 1.771 \\
\hline & SPBC25B2.02c & M-factor transporter Mam1 & 0.348 & 0.451 & 1.342 \\
\hline & SPBP16F5.03c & SAGA complex phosphatidyl-inositol pseudokinase Tral & 0.811 & 0.488 & 1.267 \\
\hline & SPAC1006.09 & MAP kinase kinase kinase Win 1 & 0.727 & 0.456 & 1.687 \\
\hline & SPBC17A3.06 & Phosphoprotein phosphatase & 2.086 & 2.02 & 0.618 \\
\hline \multirow[t]{2}{*}{ Hexose transporter } & SPAC1F8.01 & Hexose transporter Ght3 & 0.236 & 4.999 & 0.209 \\
\hline & SPCC 548.06c & Hexose transporter Ght 8 & 1.712 & 0.352 & 1.714 \\
\hline \multirow{13}{*}{$\begin{array}{r}\text { Carbohydrate } \\
\text { metabolism }\end{array}$} & SPAC22F8.05 & Alpha, alpha-trehalose-phosphate synthase & 1.032 & 0.461 & 1.630 \\
\hline & SPAC513.02 & Phosphoglycerate mutase family & 2.304 & 0.482 & 3.446 \\
\hline & SPAC513.05 & Alpha-mannosidase & 0.808 & 0.285 & 2.213 \\
\hline & SPAC $13 \mathrm{~F} 5.03 \mathrm{c}$ & Mitochondrial glycerol dehydrogenase Gld1 & 0.941 & 0.476 & 1.527 \\
\hline & SPBC8E4.04 & Aldo/ketoreductase involved in pentose catabolism & 0.902 & 0.475 & 1.698 \\
\hline & SPBPB21E7.01c & Enolase & 1.138 & 0.367 & 2.340 \\
\hline & SPBC3E7.12c & Chitin synthase regulatory factor $\mathrm{Chr} 1$ & 0.322 & 0.442 & 1.718 \\
\hline & SPAC $5 \mathrm{H} 10.06 \mathrm{c}$ & Alcohol dehydrogenase Adh4 & 0.856 & 0.463 & 1.377 \\
\hline & SPBC354.12 & Glyceraldehyde 3-phosphate dehydrogenase Gpd3 & 1.072 & 0.785 & 2.0162 \\
\hline & SPCC $1259.09 \mathrm{c}$ & Pyruvatedehydrogenase protein $\mathrm{x}$ component, $\mathrm{Pdx} 1$ & 0.542 & 0.441 & 1.305 \\
\hline & SPAC1039.11c & Alpha-glucosidase & 3.101 & 4.983 & 0.487 \\
\hline & SPBPB2B2.12c & UDP-glucose 4-epimerase/aldose 1-epimerase Gal10 & 1.361 & 2.224 & 1.309 \\
\hline & SPAC186.09 & Pyruvatedecarboxylase & 4.974 & 2.248 & 1.219 \\
\hline \multirow[t]{7}{*}{ Purine/pyrimidine } & SPCC1672.03c & Guaninedeaminase & 1.126 & 0.486 & 1.429 \\
\hline & SPAC23A1.03 & Adeninephosphoribosyltransferase & 0.863 & 2.473 & 0.427 \\
\hline & SPAPYUG7.04c & DNA-directed RNA polymerase II complexsubunit Rpb9 & 0.313 & 1.393 & 0.460 \\
\hline & SPBC19C2.03 & DNA-directed RNA polymerase I, II and III subunit Rpc10 & 0.853 & 1.384 & 0.478 \\
\hline & SPAC22A 12.05 & DNA-directed RNA polymerase III complexsubunit Rpc11 & 1.079 & 1.486 & 0.440 \\
\hline & SPBC $19 \mathrm{C} 2.03$ & DNA-directed RNA polymerase I, II and III subunit Rpc10 & 0.853 & 1.384 & 0.478 \\
\hline & SPAC19G12.04 & Ureidoglycolatehydrolase & 1.397 & 2.068 & 0.374 \\
\hline
\end{tabular}

\section{Expression levels of induced and repressed thiamine-related genes in microarray data sets}

In this study, we found that the thi3 gene, which encode no message in thiamine (Nmt1), was downregulated by 33.5 -fold in ird11 mutant cells compared to wild type cells, 
whereas it was upregulated by approximately 31 -fold in ird 11 cells after exposure to $\mathrm{H}_{2} \mathrm{O}_{2}$.

Thiamine biosynthesis and transport genes are directly influenced by the level of the thiamine pool available in the cytosol and the medium. Thiamine, as an enzymatic cofactor, regulates carbohydrate metabolism. In these microarray data sets, the 7 genes involved in thiamine metabolism were downregulated in ird11 compared to the control group. All of these genes were upregulated in ird11 after exposure to $\mathrm{H}_{2} \mathrm{O}_{2}$. Of these, the thi3/mt 1 gene was dramatically downregulated in ird11 compared to the wild type, and was upregulated in ird11 after exposure to $\mathrm{H}_{2} \mathrm{O}_{2}$. The list of genes and their relative expression changes in ird 11 under normal conditions and after exposure to $\mathrm{H}_{2} \mathrm{O}_{2}$ are shown in Table 2. Of these, the thi3-related gene was confirmed by quantitative RT-PCR (Figure 3). In qRT PCR, the level of thi3 gene expression decreased by approximately 8 -fold in ird 11 compared to the wild type, and it increased by approximately 120 -fold in ird 11 after exposure to $\mathrm{H}_{2} \mathrm{O}_{2}$.

Table 2. Changes in expression of thiamine-related genes.

\begin{tabular}{|c|c|c|c|c|c|}
\hline Function & SEQ_ID & Name & wtHP/wtC & ird11C/wtC & ird11HP/ird11C \\
\hline \multirow[t]{7}{*}{ Thiamine related genes } & SPCC1223.02 & "No message in thiamine", Nmt1 (thi3) & 0.879 & 0.029 & 31.256 \\
\hline & SPBC26H8.01 & Thiazole biosynthesis enzyme & 1.291 & 0.221 & 3.867 \\
\hline & SPAC17A2.01 & $\begin{array}{l}\text { High-affinity import carrier for pyridoxine, } \\
\text { pyridoxal, and pyridoxamine Bsul }\end{array}$ & 0.410 & 0.156 & 5.538 \\
\hline & SPBP8B7.18c & TENA/THI family protein & 0.560 & 0.359 & 2.314 \\
\hline & SPBP4G3.02 & Acid phosphatase Phol & 1.035 & 0.206 & 2.475 \\
\hline & SPCC $18 \mathrm{~B} 5.05 \mathrm{c}$ & Phosphomethylpyrimidine kinase & 0.715 & 0.453 & 2.493 \\
\hline & SPAC $23 \mathrm{H} 4.10 \mathrm{c}$ & $\begin{array}{l}\text { Thiamine-phosphate dipyrophosphorylase/ } \\
\text { hydroxyethylthiazole kinase }\end{array}$ & 1.172 & 0.602 & 2.301 \\
\hline
\end{tabular}
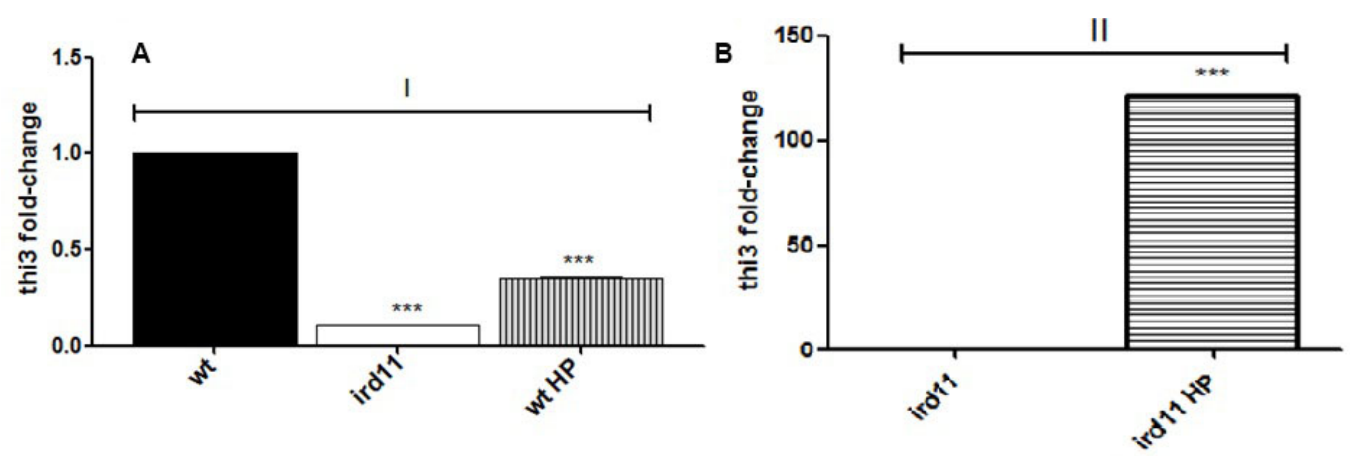

Figure 3. Expression levels of the thi3 gene relative to the act 1 gene. Expression levels of the thi3 gene in wild type and ird 11 mutant cells treated with/without $\mathrm{H}_{2} \mathrm{O}_{2}$ after grown in rich media containing $2 \%$ glucose (repressed media), were determined according to Pfaffl method. Significant differences between: A. untreated wild type and untreated ird 11 and treated wild type cells, B. untreated and treated ird 11 cells were evaluated by the Student $t$-test. $* * \mathrm{P}<0.001 . \mathrm{wt}=$ wild type; $\mathrm{HP}=$ treated with $\mathrm{H}_{2} \mathrm{O}_{2}$.

\section{DISCUSSION}

In yeast, the external glucose level controls the switch between respiration and fermentation. During aerobic conditions and high glucose concentration, $S$. pombe temporarily (during the exponential growth phase) produces $\mathrm{CO}_{2}$ and ethanol. By contrast, in conditions 
of low glucose concentration, respiration is much more highly activated, resulting in a sharp elevation in the level of ROS generation. The purpose of this study was to determine how ird11 is resistant to glucose repression and oxidative stress. Our microarray results suggested that increased ght 3 gene expression might play a role in the protection of the $S$. pombe ird 11 mutant from the deleterious effects of oxidative stress, as has been inferred in previous studies (Heiland et al., 2000; Madrid et al., 2004; Roux et al., 2010). This might clarify the lower glucose consumption rate (63\%) in ird11 compared to the wild type (Kig et al., 2005). We propose that in spite of the surplus glucose availability in the medium, the upregulation of ght 3 , which encodes the high affinity hexose transporter, may be due to erroneous starvation signaling. With the exception of ght 8 and a few of the genes listed in Table 1, no changes in the expression of other glucose-sensing signaling-related genes were observed in the microarray results.

In $S$. pombe, thiamine (vitamin B1) represses the mRNA synthesis of many genes involved in thiamine metabolism, including thi2, thi3, thi4, pho4, and carl. In addition, glucose starvation in the wild type drastically decreases the intracellular thiamine pool (Schweingruber et al., 1991). Considering the fact that thiamine acts as a vital cofactor at different stages of glucose metabolism, downregulation of the 7 genes associated with its transport and metabolism, such as thi2, thi3, thi4, and carl/bsu1, SPBP8B7.18c, and SPCC18B5.05c, may be partially explained by its potential role in the regulation of carbohydrate metabolism, growth rate, and ROS production.

Intriguingly, the microarray results showed the downregulation of $10 \mathrm{cDNA}$ elements and the upregulation of 3 cDNA elements in ird11 relative to the wild type, all of which are related to carbohydrate metabolism pathways (Table 1).

Taken together, our observations, such as the increase in ght 3 with the concurrent decrease in glycolytic enzyme enolase and thiamine synthesis/transport-related gene expression levels, may have resulted from the flux redirection toward mitochondrial respiration. Therefore, this might confer the ability to enhance NADPH generation in order to prevent the high ROS accumulation resulting from respiration. Since NADPH plays a key role as a cofactor in fatty acid synthesis, recycling steps through glutathione, thioredoxin, and peroxiredoxin pathways, its redox status is very important (Pollak et al., 2007). The reduced form of NADPH is supplied by the pentose phosphate pathway (PPP) (Slekar et al., 1996; Wamelink et al., 2008), and during stress conditions, it acts as a regulator of the expression level of some genes (Krüger et al., 2011). Ralser et al. (2007) confirmed that inactivation of GAPDH by ROS leads to redirection of the glucose flux to the PPP in order to generate more NADPH. Grüning and Ralser (2011) reported that low pyruvate kinase activity activates respiration without increasing intracellular ROS, and this adaptation is gained by stimulation of the PPP. Furthermore, our previous study showed that the reduced form of glutathione (GSH) significantly increased both in ird11 compared to wild type cells grown in normal conditions and in ird11 after exposure to $\mathrm{H}_{2} \mathrm{O}_{2}$ (Palabiyik et al., 2012).

The microarray results showed elevated levels of some purine and pyrimidine synthesis pathway-related genes. This result suggests that indeed, excessive glucose uptake by the ird 11 mutant is mainly redirected to the PPP, thereby allowing the generation of NADPH to sustain the antioxidant response, which is indispensable for cell survival. A strong effect (about 8-fold elevation) in the $f b p l$ gene expression level found in ird11 (Palabiyik et al., 2012) could be explained by activation of the gluconeogenetic pathway, which is induced by low glucose concentration sensing. In addition, the expression profiles of genes identified as rpl302 and mpg1 in the ird11 mutant by using the differential display technique provided additional evidence of this effect, suggesting that the ird11 mutant may be used as a convenient 
model cell for studies on glucose sensing/signaling and the oxidative stress response pathways (Suslu et al., 2011).

On the other hand, although the expression level of styl, which is involved in the MAPK pathway and is elicited by low glucose concentration sensing-signaling, was not altered in the ird 11 mutant compared to the wild type in normalgrowth conditions, it decreased after exposure to $\mathrm{H}_{2} \mathrm{O}_{2}$.

However, the immunoblotting results clearly showed that phosphorylated Sty1 MAPK, which is much more stable, is enhanced in the ird11 mutant, and in line with this, our microarray results indicated an approximately 2 -fold decrease in the win 1 gene expression level, which encodes Win1 MAPKKK and is located upstream of Sty1 MAPK.

Despite the low glucose concentration sensing-signaling, several lines of evidence suggested that there is a flux shift toward fermentation instead of respiration, including: 1) ird11 grows at a similar rate to the wild type, 2) no significant change in $h x k 2$ gene expression compared to wild type (Palabiyik et al., 2012), 3) the downregulation of the $p d x 1$ gene encoding pyruvate dehydrogenase protein $\mathrm{X}$ component $(\mathrm{Pdx} 1)$ and upregulation of the gene encoding pyruvate decarboxylase alongside the decreased expression of some mitochondrial genes, such as the mitochondrial glycerol dehydrogenase (Gld1) gene, gld1 and the alcohol dehydrogenase (Adh4) gene, adh4, in ird11 compared to the wild type.

The expression of gld1 is regulated by glucose repression (Matsuzawa et al., 2010). Muller et al. (1999) reported that both of the pyruvate decarboxylase genes, PDC1 and PDC5, that are conserved among yeast, bacteria, and plants, were expressed in S. cerevisiae under thiamine limitation. The PDC5 (minor form) gene was particularly repressed by thiamine. The mammalian multienzyme pyruvate dehydrogenase complex is located in the mitochondria matrix and is regulated in numerous ways such as by thiamine, ATP, NADH, and acetyl-CoA (Strumiło, 2005), and by the concerted activity of two kinases and two phosphatases (Gey et al., 2008).

Shifting to fermentation leads to a decrease in Krebs cycle activity. Consequently, the thiamine level necessary for its activation decreases, resulting in decreased thiamine transport and biosynthesis-related gene expression. Nevertheless, because of the presence of a thiamine pool in the cytosol, the PPP would be enhanced. Together, these lines of evidence indicate that ird11 cells behave as a double-edged sword.

ATP produced at a moderately high rate, alongside low glucose concentration sensingsignaling induced impairment of the respiratory chain and fermentation balance leading to behavior in opposite directions.

\section{ACKNOWLEDGMENTS}

We thank Prof. Dr. Alastair Aitken (University of Edinburgh) and Prof. Dr. Sezai Türkel (Uludağ University) for helpful advice, and Prof. Dr. Güler Temizkan (Istanbul University) and Dr. Cenk Kığ (Catholic University of Leuven) for suggestions. Research supported by the Research Fund of Istanbul University (Project \#14270 and \#20423).

\section{REFERENCES}

Byrne SM and Hoffman CS (1993). Six git genes encode a glucose-induced adenylate cyclase activation pathway in the fission yeast Schizosaccharomyces pombe. J. Cell Sci. 105: 1095-1100. 
Carlson M (1999). Glucose repression in yeast. Curr. Opin. Microbiol. 2: 202-207.

Chen BR and Runge KW (2009). A new Schizosaccharomyces pombe chronological lifespan assay reveals that caloric restriction promotes efficient cell cycle exit and extends longevity. Exp. Gerontol. 44: 493-502.

Chen D, Toone WM, Mata J, Lyne R, et al. (2003). Global transcriptional responses of fission yeast to environmental stress. Mol. Biol. Cell 14: 214-229.

Feldmann H (2010). Yeast Molecular and Cell Biology. 2nd edn. Wiley-Blackwell, Weinheim.

Flores CL, Rodriguez C, Petit T and Gancedo C (2000). Carbohydrate and energy-yielding metabolism in non-conventional yeasts. FEMS Microbiol. Rev. 24: 507-529.

Gey U, Czupalla C, Hoflack B, Rodel G, et al. (2008). Yeast pyruvate dehydrogenase complex is regulated by a concerted activity of two kinases and two phosphatases. J. Biol. Chem. 283: 9759-9767.

Grüning NM and Ralser M (2011). Cancer: Sacrifice for survival. Nature 480: 190-191.

Heiland S, Radovanovic N, Höfer M, Winderickx J, et al. (2000). Multiple hexose transporters of Schizosaccharomyces pombe. J. Bacteriol. 182: 2153-2162.

Hoffman CS (2005). Glucose sensing via the protein kinase A pathway in Schizosaccharomyces pombe. Biochem. Soc. Trans. 33: 257-260.

Kig C, Turkel S and Temizkan G (2005). Isolation and characterization of glucose derepressed invertase mutants from Schizosaccharomyces pombe. Biosci. Biotechnol. Biochem. 69: 2475-2478.

Kim SJ, Cho NC, Ryu IW, Kim K, et al. (2006). Carbon source-dependent regulation of the Schizosaccharomyces pombe pbh1 gene. J. Microbiol. 44: 689-693.

Krüger A, Gruning NM, Wamelink MM, Kerick M, et al. (2011). The pentose phosphate pathway is a metabolic redox sensor and regulates transcription during the antioxidant response. Antioxid. Redox Signal. 15: 311-324.

Lawrence CL, Maekawa H, Worthington JL, Reiter W, et al. (2007). Regulation of Schizosaccharomyces pombe Atf1 protein levels by Sty1-mediated phosphorylation and heterodimerization with Pcr1. J. Biol. Chem. 282: 5160-5170.

Lin SJ, Kaeberlein M, Andalis AA, Sturtz LA, et al. (2002). Calorie restriction extends Saccharomyces cerevisiae lifespan by increasing respiration. Nature 418: 344-348.

Madrid M, Soto T, Franco A, Paredes V, et al. (2004). A cooperative role for Atf1 and Pap1 in the detoxification of the oxidative stress induced by glucose deprivation in Schizosaccharomyces pombe. J. Biol. Chem. 279: 41594-41602.

Maeda T, Wurgler-Murphy SM and Saito H (1994). A two-component system that regulates an osmosensing MAP kinase cascade in yeast. Nature 369: 242-245.

Marshall CJ (1994). MAP kinase kinase kinase, MAP kinase kinase and MAP kinase. Curr. Opin. Genet. Dev. 4: 82-89.

Matsuzawa T, Ohashi T, Hosomi A, Tanaka N, et al. (2010). The gld1+ gene encoding glycerol dehydrogenase is required for glycerol metabolism in Schizosaccharomyces pombe. Appl. Microbiol. Biotechnol. 87: 715-727.

Muller EH, Richards EJ, Norbeck J, Byrne KL, et al. (1999). Thiamine repression and pyruvate decarboxylase autoregulation independently control the expression of the Saccharomyces cerevisiae PDC5 gene. FEBS Lett. 449: 245-250.

Nocero M, Isshiki T, Yamamoto M and Hoffman CS (1994). Glucose repression of fbp 1 transcription of Schizosaccharomyces pombe is partially regulated by adenylate cyclase activation by a G protein alpha subunit encoded by gpa2 (git8). Genetics 138: 39-45.

Palabiyik B, Kig C, Pekmez M, Dalyan L, et al. (2012). Investigation of the relationship between oxidative stress and glucose signaling in Schizosaccharomyces pombe. Biochem. Genet. 50: 336-349.

Pekmez M, Arda N, Hamad I and Kig C (2008). Hydrogen peroxide-induced oxidative damages in Schizosaccharomyces pombe. Biologia 63: 151-155.

Pfaffl MW (2001). A new mathematical model for relative quantification in real-time RT-PCR. Nucleic Acids Res. 29 : e45.

Pluskal T, Hayashi T, Saitoh S, Fujisawa A, et al. (2011). Specific biomarkers for stochastic division patterns and starvation-induced quiescence under limited glucose levels in fission yeast. FEBS J. 278: 1299-1315.

Pollak N, Dölle C and Ziegler M (2007). The power to reduce: pyridine nucleotides - small molecules with a multitude of functions. Biochem. J. 402: 205-218.

Ralser M, Wamelink MM, Kowald A, Gerisch B, et al. (2007). Dynamic rerouting of the carbohydrate flux is key to counteracting oxidative stress. J. Biol. 6: 10 .

Reiter W, Watt S, Dawson K, Lawrence CL, et al. (2008). Fission yeast MAP kinase Sty1 is recruited to stress-induced genes. J. Biol. Chem. 283: 9945-9956.

Rolland F, Winderickx J and Thevelein JM (2001). Glucose-sensing mechanisms in eukaryotic cells. Trends Biochem. Sci. 26: 310-317.

Roux AE, Leroux A, Alaamery MA, Hoffman CS, et al. (2009). Pro-aging effects of glucose signaling through a G protein-coupled glucose receptor in fission yeast. PLoS Genet. 5: e1000408.

Roux AE, Arseneault G, Chartrand P, Ferbeyre G, et al. (2010). A screen for genes involved in respiration control and longevity in Schizosaccharomyces pombe. Ann. N. Y. Acad. Sci. 1197: 19-27. 
Sansó M, Gogol M, Ayté J, Seidel C, et al. (2008). Transcription factors Pcr1 and Atf1 have distinct roles in stress- and Sty1-dependent gene regulation. Eukaryot. Cell 7: 826-835.

Schweingruber AM, Dlugonski J, Edenharter E and Schweingruber ME (1991). Thiamine in Schizosaccharomyces pombe: dephosphorylation, intracellular pool, biosynthesis and transport. Curr. Genet. 19: 249-254.

Shieh JC, Wilkinson MG, Buck V, Morgan BA, et al. (1997). The Mcs4 response regulator coordinately controls the stress-activated Wak1-Wis1-Sty1 MAP kinase pathway and fission yeast cell cycle. Genes Dev. 11: 1008-1022.

Slekar KH, Kosman DJ and Culotta VC (1996). The yeast copper/zinc superoxide dismutase and the pentose phosphate pathway play overlapping roles in oxidative stress protection. J. Biol. Chem. 271: 28831-28836.

Strumiło S (2005). Short-term regulation of the mammalian pyruvate dehydrogenase complex. Acta Biochim. Pol. 52: 759-764.

Suslu KG, Palabiyik B and Temizkan G (2011). Genes involved in glucose repression and oxidative stress response in the fission yeast Schizosaccharomyces pombe. Genet. Mol. Res. 10: 4041-4047.

Walker GM (1998). Yeast Physiology and Biotechnology. John Wiley \& Sons, Chichester.

Wamelink MM, Struys EA and Jakobs C (2008). The biochemistry, metabolism and inherited defects of the pentose phosphate pathway: a review. J Inherit. Metab. Dis. 31: 703-717.

Wilkinson MG, Samuels M, Takeda T, Toone WM, et al. (1996). The Atf1 transcription factor is a target for the Sty1 stress-activated MAP kinase pathway in fission yeast. Genes Dev. 10: 2289-2301. 